\title{
RECONCILING NEGATIVITY WITH POSITIVE LEADERSHIP: A PRACTICAL APPLICATION
}

\author{
Chak Fu Lam ${ }^{a}$, Christopher Roussin ${ }^{b}$ \\ ${ }^{a}$ Sawyer Business School, Suffolk University, Boston, MA, USA, \\ e-mail: cflam@suffolk.edu \\ boston Children's Hospital, Harvard Medical School, Boston, MA, USA, \\ e-mail: christopher.roussin@childrens.harvard.edu
}

\begin{abstract}
Purpose: The main goal of this article is to reconcile the concept of negativity with positive leadership approaches in a real-world setting.

Methodology: We interviewed Mr. Paul Fayad, ex-President \& Chief Executive Officer (CEO) of HHA Services, to describe his experience in implementing positive leadership and the role of negativity, and superficially negative behaviors, in creating an engaged workforce.

Findings: Effective positive leadership is not unerringly optimistic in all moments and in all things. Instead, it is a responsibility to create a positive work environment for everyone working in your company. This means that managers have to not only keep their people happy, but also eliminate the negative, which can be the wrong people, the wrong process, the wrong equipment, or other processes that should be eliminated. In the elimination of this negative, sometimes critical (or focused-negative) behaviors are required of the "positive leader".
\end{abstract}

Implications: Negativity is a part of positive leadership, especially during the hiring process and critical conversation. The importance of addressing negativity is discussed.

Keywords: Positive leadership, critical conversation, human resources

Paper type: Viewpoint

\section{Introduction}

Research and practice on positive leadership has burgeoned over the past two decades. The basic premise of positive leadership is that "people have a tendency to move toward positive energy and away from negative energy", (2013) and that negativity can be overcome by emphasizing on the positive. Since the introduction of positive psychology in the mainstream business media (Seligmann and Csikszentmihalyi, 2000), many scholars and management consultants have embraced positive leadership concepts in the corporate world (Cameron et al., 2003). A quick search on the EBSCO Business Complete using the term "positive 
RECONCILING NEGATIVITY WITH POSITIVE

Chak Fu Lam Christopher Roussin leadership", "positive leader", "compassion", "gratitude", and "strength" returns more than 500 articles, and Cameron et al.'s (2003) pioneering book entitled "Positive Organizational Scholarship: Foundation of a New Discipline", has yielded more than a thousand citations on Web of Science. Case exercises concerning such positive activities as job crafting (Berg et al., 2009), Everest goals (Cameron and Plew, 2012), appreciative inquiry (Cooperrider and Whitney, 2005), and reflected best-self feedback (Quinn et al., 2003) are in-demand as tools to address the need for positivity in the corporate world.

Despite the popularity of positive leadership, some have raised serious concerns about its exclusive focus on positivity in all things, marginalizing the situational role and purpose of negativity in the workplace. For instance, Tennen and Affleck (2003) wrote that "to simultaneously experience positive and negative emotion towards the same person; to appreciate the good in people who hurt one could easily join positive psychology's catalogue of human strengths". Learmonth and Humphreys (2011) openly suggested that eliminating the negative is "dangerous", because it fails to acknowledge that work is experienced by most people as negative, and because it eliminates the possibility that something negative may be perceived as positive by others. Fineman (2006), in his essay critiquing positive scholarship, wrote that the separation between positive and negative is "arguable", because negative, stressful events that lead to fear, frustration, and anxiety are core to one's identity formation and may contribute to personal and social development. By focusing on the positive, Fineman posited, positive leadership would stigmatize "negative thinkers" whose life experiences and workplace difficulties may justify their anxiety and distress but nevertheless do not fit with the positive template. His criticism is consistent with Furedi's (2003) idea that focusing on the positive may inadvertently pathologize those who experience negative emotions, resulting in the perception that negativity is abnormal and requires treatment.

\section{Method}

In the section that follows, we offer something rare in academic writing: exposure to raw, uncut data in the form of an interview about positive leadership with an executive who very consciously practiced positive leadership as CEO of a successful mid-sized organization. The goal of this interview was to elicit specific insight on the debate concerning the role of negativity in positive leadership. The interview is with Mr. Paul Fayad, former President and CEO of HHA Services, a healthcare support service management company with over 5000 employees nationwide. HHA Services was sold in 2012 to ABM, and is now called ABM Healthcare. 
2.1. Paul Fayad, ex-President \& CEO of HHA Services

When Mr. Fayad entered his position, turnover and employee dissatisfaction was a critical issue. Employees were unhappy with the upper management, thirdparty customer service scores on cleanliness and courtesy were so low that it was non-existent, and turnover reached almost 50\%. Mr. Fayad's educational focus on organization behavior for his Master's degree and his master thesis on self-developed work teams provided the basis for positive leadership at HHA Services. Immediately, Mr. Fayad designed the Quality School, a two-day training program for all new supervisory, management and executive hires to learn about Total Quality Management and creating an engaged workforce. $\mathrm{He}$ also had to let go of more than $50 \%$ of his workforce who did not buy into the concept of positive leadership. Within two years of positive leadership inception, employee satisfaction increased and turnover decreased to below $20 \%$ and ultimately to below $10 \%$. Mr. Fayad then began to work directly with healthcare centers, medical facilities, and associations to provide seminars and keynote speeches on positive leadership and employee engagement, establishing positive work environments, and developing positive leaders. HHA Services went on to win Best places to work in Southeast Michigan every year, Best places to work in the State of Michigan, and best places to work in Health Care nationally. HHA was also awarded the Second highest Michigan based Malcom BaldridgeNavigator Award. At the same time, Mr. Fayad has written numerous articles for healthcare trade journals, and has written, directed and produced videos on Customer Service and Service Recovery. This caught the attention of the first author of this article. They began collaborating on studying HHA Services on positive culture, examining the importance of human flourishing, thriving, and energy on organizational performance, and establishing a long-term relationship with several Universities in the United States.

Upon leaving HHA Services, Paul turned his focus on his passion: Corporate education and executive coaching. In 2012, Mr. Fayad created Positive Leader, Inc., a company focused on providing the most current management development focusing on employee engagement and establishing positive culture at organizations. In early 2013, Mr. Fayad and a few other investors bought eLearning Mind (eLM), which provides custom online corporate learning and training. Currently, Positive Leader and eLM are collaborating on a series of e-learning modules on employee engagement through positive leadership. In addition, Mr. Fayad continues to provide seminars, workshops, webinars and oneon-one executive coaching on leading positively. Mr. Fayad was often invited as a guest speaker, presenting real world management issues and provided students practical solutions from the lens of a positive leader.
RECONCILING

NEGATIVITY

WITH POSITIVE

Chak Fu Lam

Christopher Roussin 
RECONCILING

NEGATIVITY

WITH POSITIVE

Chak Fu Lam

Christopher Roussin

\subsection{The Interview}

The following interview consists of three parts. In the first part, we asked Mr. Fayad to define positive leadership and why he believed that positive leadership would work. In the second part of the interview, we asked Mr. Fayad how he successfully implemented positive leadership. In the final part, we ask Mr. Fayad what he would recommend for managers interested in implementing positive leadership. We end with concluding thoughts by integrating Mr. Fayad's experiences in implementing positive leadership with research on human resource and critical conversation.

Interviewer: Mr. Fayad, what is your definition of positive leadership?

Fayad: Positive leadership may mean different things to different people; it does not mean the same to everyone, so I'm speaking only for myself. For me, positive leadership means leaders and managers focusing on positive behaviors and outcomes. It is an attempt to find what is right within the organization and then create an environment so that these positive outcomes can be repeated and mirrored throughout the organization. It's the opposite of finding what's wrong and fixing it.

Interviewer: What convinced you that Positive Leadership would work?

Fayad: What got me into positive leadership is my knowledge and understanding of Total Quality Management (TQM). TQM is an attempt to discover what is wrong and eliminate those problems, which is not a bad way of management because you get results. But when you focus on the negative, you are constantly reminding people of all the things that they are doing wrong, and it tends to wear people down after a period of time. For example, we are achieving $98 \%$ positive outcomes, and so let's get rid of the $2 \%$ negative outcomes, and everybody is looking at you and saying, "We get $98 \%$ of positive outcomes but we don't get recognition for those positive outcomes". So within the positive leadership framework, what we do is to focus on positive behaviors and positive outcomes. When you focus on positive behaviors and outcomes, you have employees, supervisors, and managers all in a better mood, less stressed, and feel good about what they do. Therefore they tend to work harder and produce better outcomes.

Interviewer: Can you elaborate more on what you mean by focusing on the positive? 
Fayad: What I mean is that when you focus on the positive, you are really trying to build relationships between people - the relationships between corporate executives, the relationships between executives and managers, the relationships between managers and subordinates, and so forth. It is not just focusing on the idea that we are always going to have positive outcomes. It is about the feeling that people have and the culture that is established in the relationships with managers and subordinates. You also want the associates to establish relationships with each other. A great example is Habitat for Humanity. There you have a group who has the same vision and entire team having the same desire to produce positive outcomes. This is because you have like-minded people with high levels of compassion and empathy. They can do something that nobody else can do. They share a common vision, and desire a common outcome. So people enjoy the job more, enjoy each other more, and there is higher degree of proactivity. Relationships are the core values to positive leadership: when you have a negative manager or a manager who is more traditional and does not understand the concept of positive leadership in leading people, it destroys the culture and the positive employees will ultimately leave.

Think of housekeepers in a medical facility. How do you motivate them? The task alone may motivate them for a period of time, but eventually that motivation will subside, and the task will become just a series of things they do. But if they have relationships with people such as the patients or nurses while they are performing their cleaning duties, other people treat them positively, their leadership excites them by telling them that their job is important, sharing with them positive stories and best practices, then the housekeepers will see a greater good of what they do through the relationships they have. In the housekeepers' heart, it is not the task, but it's what they are doing for other people that makes them feel good what they do, and they witness it in action. In medical facilities where there is a positive culture, where people treat one another with respect, kindness, and gratitude, infection levels were down, morale was high, and retention was better. Relationships change everything.

Interviewer: Share with us how you implemented positive leadership at HHA services.

Fayad: Very slowly, and very systematically. In instituting positive leadership, the responsibility that I felt was not just to make money or grow the company, but provide a living for other people, that they will be proud of. When I took over the company, it was somewhat different. The mentality was old: something was wrong, fix it. But it wasn't working. It worked for a period of time, but it wasn't something that would get us in the future. 
RECONCILING NEGATIVITY WITH POSITIVE

Chak Fu Lam Christopher Roussin
One day a housekeeper came to me to provide feedback about his medical facility, and it got me thinking why people still came to me as a CEO, rather than talking to their supervisor. The realization was that implementing positive outcomes and creating a positive culture is a top-down process, not a bottom-up process. I took a look at the corporate office, and made the decision that we had to change the philosophy of executives and leaders within the organization, that we were not the executives or leaders but we were the server, and those at the location of the facility were the leaders. So we were the one that had to help the leaders be successful, not making us successful.

By doing that, we created a different process, and we began to see people that can accomplish this process, and we had to get rid of the people who couldn't accomplish this process. If they didn't see it and they didn't agree with this philosophy, they couldn't stay. Because you make a commitment to a route that you have taken, you have to follow it. We have done a lot of work to thin the herd of all the naysayers after realizing that they were not going to change.

Interviewer: So the first step of creating a positive culture is to get rid of people who are negative. That doesn't sound entirely positive.

Fayad: First, I don't think anything that we do is negative. A lot of CEOs, executives, and practitioners misunderstand the concept of positive leadership. People feel that positive leadership is Pollyannaish: that nothing is negative - you can't correct, you can't do critical conversation, you can't fire people.

It's really the opposite of it. Positive leadership is a responsibility to create a positive work environment for everyone working in your company. This means that you have to not only keep your people happy (and happiness is important and I recommend people to search out ways to make other people happy), but also eliminate the negative, which can be the wrong people, the wrong process, the wrong equipment, or other low hanging-fruits that can be easily eliminated. It has to do with critical conversation, talking to people and get jobs done correctly. Firing people if you have to.

The challenge that many organizations face today is that people make their way into leadership positions because they are so good at the task but not so good at building relationships. Does this person really understand the concept of positivity? Will this person see the advantage of a positive organization? No, not in a million years. It is never going to happen. They don't get it. And if you can't form positive relationships, you can't produce positive outcomes. You can force people to do their work through task management, or you can threaten people to get positive outcomes, but the minute you turn your back to your people, they are not going to do what you want them to do. If leaders are not naturally oriented 
toward positive outcomes, relationship-driven, compassion-driven, they are not going to be able to lead in a positive leadership fashion.

Here is the bottom line: The good of the many outweighs the good of the few or the one. Positive leadership is not a Pollyanna view of society. You have to engage in something seemingly negative to create a more positive culture.

Interviewer: How long did it take you to let go of your (negative) staff and start all over?

Fayad: With corporate executives, you have to do it very quickly, not only because they are the most dangerous in ruining the kind of culture you want to build, but also because they can find a new job a lot quicker. So it's a matter of closing the door and sitting down and telling them that they have to go, or they could stay but they have to start looking for a new job actively.

When you go further down the ladder, you have to be careful about how you do it and how quickly you do it. Everybody needs to understand the process and if they can't follow the process, then we sit down with them and have a critical conversation. After a couple of critical conversations, we would either let them go or they would realize that they do not fit in the culture anymore. The faster you remove people who do not understand or refuse to buy into the positive leadership concept, the better it is. I replaced about $50 \%$ of the leadership at HHA. It was a difficult period of time but that's a major reason how we end up creating a more positive culture and winning all the best-place-to-work awards.

Interviewer: Why don't you try keeping your existing people so that those who are not as positive can become more positive?

Fayad: The one thing we have learned over the years from academic research is that some people are inherently more capable of building relationships, being more compassionate and empathetic than others. These traits are very difficult to learn. And even if they could be learned eventually, the amount of time and effort managers would need to spend to produce high levels of compassion and empathy is high. We also know that people who have the tendency to be happy have a greater ability to be positive and are open to the concept of positive leadership. Through my executive experience, if managers and leaders do not understand the importance of building positive relationships, showing compassion, and showing empathy, it is best not to hire them, as it will take too much time to teach them how to lead positively. It does not make business sense to focus your time on the negative people. Rather, it is better off to focus on the positive people, create a strong positive environment so that they produce extraordinary results within a shorter period of time. 
RECONCILING NEGATIVITY WITH POSITIVE

Chak Fu Lam Christopher Roussin
Interviewer: How do you go about identifying the negative people in your company?

Fayad: Let's be very careful about concluding whether someone is positive or negative. There are grey areas. Most likely you have a range of people, and you have people on one scale who are naturally oriented towards being positive. You have on the other end of the scale the negative people. It's something that they don't see. When you are born this way, you don't see yourself as a negative person, because you live your life. They tend to be egocentric and narcissistic, which creates an even greater problem because now they really don't see their negativity. People who are negative show themselves day after day. Everybody sees it, this is the person who comes in day after day and complains about everything.

Then you have degrees and the in-betweens who are right at the border. For people who are in the middle but can't make the turn: you have to give them a bit more time. You have to see how they react and fit, and if they don't see it, you move them away. So it's a mix. It's not black and white. Remember, positive people may suffer dark period of times, such as change of jobs, going through a divorce, having a sick parent, or any stressful events on a given day, but ultimately they will convert back to positive people. So as a leader, we have to be careful.

\section{Interviewer: What's next after letting your "negative people" go?}

Fayad: We have to re-establish our hiring process. We can't bring in existing people from other organizations who are equally negative. The interview process is extremely emotional, especially when you are in a hurry. So you hire the same type of people who you just let go. The hiring process becomes very laborintensive. What ended up happening was that we began to use a personality assessment so that we could identify potentially negative employees. We assessed dimensions that we believed were key to building a positive culture-empathy, gratitude, humility, emotional intelligence, and compassion to say a few. We let thousands of people take it, and soon enough we created a database where we could compare candidates with our existing database, and made a decision on whether the candidate could proceed to the next phase of the hiring process, which was the in-person interview. It was a great process, because you removed everyone away from the interview process, which is very emotional, and the interviewers tend to provide interviewees with an opportunity to win.

Interviewer: Let's say you have a company now with all "positive people". What's next? 
Fayad: You build on this. You create opportunities that allow your people to be successful. You do this by mirroring. Mirroring is when you find staff that have improved processes. You identify that their work is exceptional, you recognize them in public, you reward them and then implement that process throughout the organization where it applies. A positive leader is "positive" process driven. As positive leaders we find what our staff is doing right and we mirror the positive process.

(Being a) positive leader is also relationship-driven focus...knowing the people that work for me, having a positive relationship with those who work for me, understanding that one day they may have a problem and I can help them so that they can go back to being positive. How can we be focused on positive outcomes if we have not established a relationship with our staff? And without relationships then we won't be able to establish a positive culture.

Interviewer: What if someone makes a mistake? How can you be positive in this situation?

Fayad: You need to engage in a critical conversation with them. In a critical conversation, you are not trying to embarrass the person who made the mistake, but really you are trying to help that person improve and do a better job next time. The purpose of a critical conversation is to provide a learning opportunity for the individual. But people make the mistake of sugar-coating during the process. Most critical conversations that are mishandled involve the manager feeling guilty about performing the conversation and sandwiching the issue between two kind, positive statements. This confuses the employee and does not focus on the learning process of the conversation. Respect is important during the process. We provide respect throughout the process by focusing on the outcome that needs improving and not using terminology that is personal in nature. Providing alternative positive processes is therefore an important part of the critical conversation.

Interviewer: What would be your recommendation if executives are interested in implementing positive leadership?

Fayad: A better understanding of what positive leadership is will be most important. When you look at implementing positive leadership, you have to prepare yourself for it. You can start out simply by focusing on what is right; all the things that people do well, appreciating those things, and identify them. Approach them and ask, "how do you do those things so well and so often?" Get feedback from people. That alone itself is positive leadership, because it forms a relationship and an interest on a managerial level for people to say "my goodness this person is 
RECONCILING NEGATIVITY WITH POSITIVE

Chak Fu Lam Christopher Roussin

Table 2.

Synthetic evaluation value attributes for selection strategy

38 really interested in how good I'm doing?" In a typical day in most organizations there is not a lot of relationship management, let alone positive management. Managers usually walk around and look for tasks that need to be completed and/or corrected. Now suddenly a manager is walking around appreciating the 7.5 hours of work that is being done correctly, that person becomes more positive. Maybe they might start out thinking that something is wrong with my boss, but over time they will realize that this person has a deep understanding of what I do and wants to understand how I do it well.

Then you establish process-a strategy and how do I form a habit so that I can do it on a daily basis, so that I don't just do it once a week, but I do it regularly. You establish a strategy, learn more about positive leadership, implement immediately by changing how you view people's work pattern, by looking at positive outcomes and you build on it. That's a simple way of starting it.

Now there will always be times when you will have issues arise that need correction. As a positive leader you must approach these issues as anomalies that need to be addressed as part of the learning process. The differences between a positive leader and a regular leader is that positive leader expect great results instead of anticipating and looking to find errors.

\section{Concluding Thought}

In reviewing Mr. Fayad's interview, we were impressed by his revelation that positive leadership principles were both satisfying and effective to practice. We were most impressed that Mr. Fayad's remarks shows that negativity, in a number of forms, is a part of his personal definition of positive leadership-a definition that he developed over many years of practice. Clearly, incorporating negativity in certain planned ways has been just as important for Mr. Fayad as more overtlypositive behaviors in the overall creation of a positive work environment. Below, we highlight two such areas where negativity plays a role in creating positive outcomes: Human Resource Practice and Critical Conversation.

\subsection{Human Resource Practice}

In contrast to Fineman's (2006) criticism that positive practices discriminate against the "negative thinker", Mr. Fayad is clear that there is room for some critical, or focused-negative, thinking in managerial processes that encourage positive cultures. Interestingly, "positive" leadership can be, momentarily, negative in tone. However, he is also clear that this critical behavior exhibited by managers should be expressly used to discriminate against overtly negative individuals who may threaten the culture of the organization, especially during the hiring process, for the benefit of the organization. Such a practice ensures that negative individuals-those who exhibit selfish, egocentric, and narcissistic traitsdo not become part of the organization and subsequently create, or contribute to, 
a toxic culture. The notion of hiring the most positive people is consistent with Southwest Airline's corporate culture of fun, in which the airline seeks "positive people" to create a positive culture (Deal and Kennedy, 1999). Likewise, when dealing with people who contribute to a negative culture, Mr. Fayad insists that it was important to remove them very quickly, especially those who occupy top management levels. In the process of removing these people, behaviors that are considered negative are required by the culture-reinforcing manager.

Bill Walsh, a successful NFL coach who has won three Superbowl championships, was ready to get rid of his most talented players if these players contributed to a negative organizational culture (Walsh et al., 2009). In terms of management practice, the majority of companies usually hire employees based on their skills. As suggested by Mr. Fayad, hiring people based on functional, taskoriented, skill will not accomplish the creation of a positive work environment. Instead, employees should be recruited for both functional skill and for desired personality traits such as empathy, compassion, and other traits that are conducive to the creation of a positive work environment. From a theoretical perspective, Mr. Fayad's interview suggests that positive scholarship could broaden its stance with respect to hiring practices. Although one may think that, as positive leaders, we should be kind (i.e. positive!) to our people by attempting to develop them, Mr. Fayad suggests that it might be better to remove them and instead hire those who have the capacity to build relationships with others, show compassion and empathy, and demonstrate positive leadership. Thus, an important theoretical research question to examine is how organizations should hire to create and sustain a positive culture.

\subsection{Critical Conversation}

To create a positive work environment, Mr. Fayad noted that it is important for managers and executives to engage in critical conversation, which many managers avoid due to its superficial appearance of negativity. Mr. Fayad does not perceive critical conversation as negative-as long as it is executed in a formal, professional manner. In practicing his personal version of positive leadership, $\mathrm{Mr}$. Fayad noted that he avoided being perpetually "nice", instead balancing a larger set of behaviors (including respectfulness, kindness, and directness) to create a more substantial, durable positivity in the work environment. He noted that many managers and corporate executives mistakenly think that they need to be "nice" in critical conversation. This is perhaps evidenced by a popular approach known as the sandwich technique, in which managers will praise or say something positive about the employee, followed by negative feedback, and further followed by more positive statements to preserve the ego of the employee. On the contrary, Mr. Fayad expressed his belief that such a technique is not positive but instead unclear and ultimately negative, because managers using this technique are sending mixed 
RECONCILING NEGATIVITY WITH POSITIVE

Chak Fu Lam Christopher Roussin signals with respect to their employee's skillset. A positive critical conversation focuses on describing the consequences of their mistakes and providing positive alternatives to their ineffective behaviors. "Sugar-coating" (as evidenced by the sandwich technique) is a destructive element in Mr. Fayad's view, and should be completely eliminated. A manager's objective is not to inflate, flatter, or otherwise deceive the employee; rather, it is to respectfully and efficiently help the employee improve his or her performance.

The interview also provides an important theoretical implication for research on positive organizational scholarship. Theoretically, critical conversation (also known as crucial conversation, supportive communication, and developmental feedback) has been a popular topic of interest in some positive organizational scholarship. Kluger and Denisi's (1996) meta-analysis research on developmental feedback suggests that when feedback is geared toward skill improvement, performance tends to improve. By contrast, when feedback is perceived as personal and insulting, individual performance tends to reduce. Their finding is consistent with the concept of critical conversation as discussed by Mr. Fayad. A promising area for future research is to examine the effectiveness of specific tactics or strategies that managers may employ in creating a positive culture through critical conversation an area that is currently missing in the positive scholarship literature.

\section{References}

Berg, J.M., Dutton, J.E., Wrzesniewski, A. (2008), The Job Crafting Exercise, University of Michigan: Centre for Positive Organizational Scholarship, available at: http://posi tiveorgs.bus.umich.edu/cpo-tools/job-crafting-exercise/ (accessed 22 June 2015).

Cameron, K., Dutton, J., Quinn, R. (2003), Positive organizational scholarship, Berrett - Koehler, San Francisco.

Cameron, K.S., Plews, E. (2012), "Positive leadership in action: Applications of POS by Jim Mallozzi”, Organizational Dynamics, Vol. 41 No. 2, pp. 99-105. DOI: http:// dx.doi.org/10.1016/j.orgdyn.2012.01.003

Cooperrider, D.L., Whitney, D. (2005), Appreciative inquiry: A positive revolution in change, Berrett-Koehler, San Francisco.

Deal, T., Kennedy, A. (1999), The new corporate cultures, Textere, London.

Fineman, S. (2006), "On being positive: Concerns and counterpoints", Academy of Management Review, Vol. 31 No. 2, pp. 270-291. DOI: http://dx.doi.org/10.5465/ AMR.2006.20208680

Furedi, F. (2003), Therapy culture: Cultivating vulnerability in an uncertain age, Routledge, London.

Kluger, A.N., DeNisi, A. (1996), "The effects of feedback interventions on performance. A historical review, a meta-analysis, and a preliminary feedback intervention theory", Psychological Bulletin, Vol. 119 No. 2, pp. 254-284. DOI: http://dx.doi. org/10.1037/0033-2909.119.2.254

Learmonth, M., Humphreys, M. (2011), "Blind spots in Dutton, Roberts and Bednar's 'Pathways for positive identity construction at work': 'You've got to accentuate the 
positive, eliminate the negative", Academy of Management Review, Vol. 36 No. 2 , pp. 424-427.

Quinn, R.E., Dutton, J.E., Spreitzer, G.M. (2003), Reflected best self-exercise, MI: Center for Positive Organizational Scholarship, University of Michigan, Ann Arbor.

Seligman, M.E.P., Csikszentmihalyi, M. (2000), "Positive psychology: An introduction", American Psychologist, Vol. 55 No. 1, pp. 5-14. DOI: http://dx.doi.org/10.1037/0003066X.55.1.5

Tennen, H., Affleck, G. (2003), "While accentuating the positive, don't eliminate the negative or Mr. In-Between", Psychological Inquiry, Vol. 14 No. 2, pp. 163-169.

Walsh, B., Jamison, S., Walsh, C. (2010), The score takes care of itself: My philosophy of leadership, Penguin Group, New York.
RECONCILING

NEGATIVITY WITH POSITIVE

Chak Fu Lam

Christopher Roussin 